\title{
O Prêmio nobel e o burocrata: a conformação de um campo intelectual no Direito do Trabalho na Aroentina da década de 1930
}

Norberto O. Ferreras*

Resumo: $O$ presente trabalho tem por objetivo realizar uma aproximação à conformação de um campo intelectual vinculado com o Direito Trabalhista na Argentina. Para isso, serão abordadas as disputas estabelecidas por importantes figuras do Direito Trabalhista daquele país em relação aos significados da Organização Internacional do Trabalho (OIT). Tais disputas foram travadas pelo Ministro das Relações Exteriores da Argentina, Carlos Saavedra Lamas, e um obscuro funcionário do mesmo Ministério, Raul Migone. O controle desta relação permitia a legitimação de um discurso e uma prática nesta área de ação.

Palavras-chave: Direito Trabalhista. Intelectuais. Organização Internacional do Trabalho. Argentina.

\section{Introdução}

O presente artigo tem por objetivo discorrer sobre a formação de um campo intelectual e compreender o que é um intelectual, a

\footnotetext{
*Professor do Departamento de História da Universidade Federal Fluminense (UFF). E-mail: ferreras@vm.uff.br
}

Anos 90, Porto Alegre, v. 16, n. 29, p. 213-236, jul. 2009 
partir de um caso muito específico: o início do funcionamento de um sistema de correspondentes por parte da Organização Internacional do Trabalho (OIT) na América Latina, mais precisamente na Argentina.

A designação do correspondente e a sua continuidade no cargo se apresentam como momentos decisivos da ratificação das suas credenciais, as quais se relacionam com a produção e vínculos profissionais, acadêmicos e também políticos. Devemos esclarecer por que podemos considerar esses funcionários como intelectuais e, para isso, será preciso realizar uma análise do conceito de "intelectual”, sobretudo pela relação entre pensamento e ação, entre planejamento e execução. Certamente, um intelectual, de maneira geral, tem que pensar e refletir sobre a sociedade, a política e a cultura, mas não unicamente.

Além disso, é necessário determinar a latino-americanidade desses intelectuais. Definir o que é América Latina para esses atores implicará uma redefinição desse conceito e o entendimento da relação que se estabelece com a Europa e os Estados Unidos. O que estará presente em todo momento será a possibilidade de pensar a América Latina como o lugar em que uma instituição de tipo internacional e multilateral se estabelece. Que papel correspondia a esta região? Quais as expectativas sobre ela? Por que entendiam que era preciso uma aproximação da OIT com a América Latina? Havia alguma utilidade mútua ou simplesmente pesava a intenção de controle?

Neste artigo, abordaremos essas questões em relação a um caso específico: a Argentina na década de 1930. É impossível estabelecer uma correlação direta entre a Argentina e o resto da América Latina. Além disso, quando se consideram as peculiaridades deste país, é preciso pensar em como ele é definido em relação à Europa, mas também e principalmente em relação ao resto da região.

Por último, este artigo é parte de uma pesquisa que estou desenvolvendo sobre a OIT e os vínculos que ela estabeleceu com 
a Argentina e o Brasil. Por isso, grande parte das fontes utilizadas diz respeito à correspondência entre os membros da OIT. Esses documentos permanecem inéditos por serem informes oficiais ou oficiosos ou por se tratar de correspondência pessoal ou administrativa. Outra parte das fontes está editada e pode ser facilmente consultada em bibliotecas ou arquivos institucionais da Argentina. A pesquisa sobre a OIT demanda a visita de bibliotecas desta instituição ou bibliotecas e arquivos relacionados a ela.

\section{Os intelectuais em questão}

$\mathrm{O}$ aspecto mais importante para poder desenvolver este artigo é definir o que é um intelectual ou quem pode ser considerado um intelectual. Esta é uma discussão que tem uma longa trajetória e que não será totalmente resenhada aqui. ${ }^{2}$

Há uma tendência clássica em utilizar o termo "intelectual" para denominar aqueles que pensam a sociedade como um todo, propondo respostas e soluções para ela. No entanto, podemos e devemos ampliar esta definição a outros atores. A delimitação daquilo que é um intelectual oscila entre a tentativa de restringir esta categoria ao mínimo ou, ao contrário, a aspectos muito amplos. Dessa forma, é difícil determinar quem pode ser incluído ou não nesta categoria. $\mathrm{O}$ debate se esteriliza se ficarmos presos à delimitação das fronteiras de quem dever ser considerado digno de merecer essa designação. Contudo, isso não nos isenta de ter que pensar, com outros analistas dos chamados "intelectuais", o conceito e a quem ele pode ser atribuído.

Para começar, temos que questionar o estereótipo de que todo intelectual deve ser crítico, ou seja, aquele que contesta abertamente as ideias dominantes na sua sociedade. Tal concepção está presente na definição de "intelectual" desde que a palavra foi cunhada como forma de agredir os defensores do Capitão Dreyfus, durante 
o processo que levou a sua condenação na Ilha do Diabo. ${ }^{3}$ Mais especificamente, a certidão de nascimento do termo "intelectual" se produziu no momento em que cientistas, jornalistas e professores universitários participaram, em 1898, do abaixo-assinado redigido por Émile Zola a favor de Dreyfus.

Assim, de uma crítica, a palavra passou a designar um grupo de indivíduos que questionava a ordem vigente e que propunha alternativas a ela. Porém, aos poucos, esse termo passou a designar muitos grupos diferentes, integrados unicamente pelo peso e fascinação desta palavra. A proliferação foi tão extensa que, no ano 2000, Pierre Nora se queixava de não mais saber quem era um intelectual, verificando, aliás, tanto seu fim quanto sua excessiva abundância (NORA, 2000). Naquele mesmo ano, Régis Debray, partidário de outra posição política, apresentava a mesma percepção de Nora sobre o fim ou a morte do intelectual (DEBRAY, 2000). E é possível que ambos estivessem certos se pensarmos em determinados tipos de intelectuais. Para Nora, não existiam mais os maîtres à penser, entendidos assim aqueles que seriam formuladores de esquemas de pensamento ou os forjadores de ideias. Já para Régis Debray, não existiam mais os intelectuais engajados que deveriam agir tanto no terreno das ideias quanto da prática. Assim, em ambos os casos, o que estaria em falta seriam os intelectuais como eles próprios: que pudessem criar influentes revistas de ideias (como Pierre Nora) ou de lutar nos terrenos das ideias e da política (como Régis Debray).

Esta pequena reflexão teve por objetivo mostrar a dificuldade existente na definição daquilo que é um intelectual. François Dosse nos alerta para a proliferação de significados e chama a atenção para a existência de dois registros no uso da categoria intelectual: o registro nominalista e o substancialista. Mesmo que, em qualquer definição, os dois registros estejam presentes, no primeiro prevaleceria o compromisso e o engajamento nas lutas políticas e sociais. Este é um registro cultural que delimita o grupo dos intelectuais ao das elites criativas, principalmente aquelas que apresentam um 
compromisso político. O segundo é um registro social, no qual o que interessa é o pertencimento a um determinado grupo socioprofissional, enfatizando-se a divisão, no interior da sociedade, entre aqueles que trabalham manual ou intelectualmente (DOSSE, 2007, p. 19).

Pierre Bourdieu, por exemplo, parte da metáfora dos campos magnéticos. $\mathrm{Na}$ medida em que os intelectuais se constituem como um campo autônomo ou que se tornam independentes de formas externas de sujeição, podem ser definidos segundo a relação que têm uns com os outros de acordo com as formas da atração ou repulsão entre si. Sem proporcionar uma definição específica do intelectual, Bourdieu entende que este é aquele indivíduo que trabalha no âmbito da cultura, assimilando o aspecto intelectual ao cultural (BOURDIEU, 2002, p. 9-50.).

Esta reflexão parte das ideias de Antonio Gramsci sobre o lugar que cabe aos intelectuais na sociedade, havendo uma distinção entre aqueles que optam por serem os "verdadeiros" intelectuais, ou seja, o literato tradicional, e o intelectual "novo", aquele que opta por unir-se à causa proletária. Porém, mais interessante é observar a forma como Gramsci alarga a denominação de "intelectual" a todo o gênero humano, demonstrando que não existe atividade humana sem reflexão nem planejamento prévio. Certamente, essa é uma posição extrema utilizada pelo autor para depois delimitar a categoria de intelectual à qual incorpora os funcionários públicos. Gramsci escreve no momento da expansão do Estado e, portanto, do funcionalismo público na mão do fascismo. Para ele, os funcionários públicos fazem parte do sistema coercitivo ou de legitimidade do Estado (GRAMSCI, 1979, cap. 1). Recupero aqui esta abordagem gramsciana no âmbito da relação entre Estado e intelectualidade, não para elaborar uma qualificação como a realizada por Gramsci, mas para poder compreender algumas questões sobre os intelectuais em sua relação com o Estado.

Desde outro ponto de vista, Jean-François Sirinelli parte de uma anedota para mostrar a dificuldade existente na definição do 
intelectual: em 1933, um grupo de antifascistas franceses devia determinar o que significava o termo e a quem devia aplicar-se. Depois de um árduo debate, chegaram à conclusão de que ser intelectual era uma "qualidade humana" (SIRINELLI, 2003, p. 241). Pode ser este o critério para decidir quem podemos considerar como intelectual?

Sirinelli (2003, p. 242) e Dosse (1997, p. 28) coincidem no caráter polifônico e polimórfico da categoria de intelectual, ao que podemos agregar também a mutabilidade do termo ao longo do tempo. Isto faz com que a categoria seja ora restrita, ora mais ampla; ora inclusiva, ora excludente. Dentro desse caráter polifônico, polimórfico e mutante, temos a opção de nos restringir ao engajamento ou, pelo contrário, podemos pensar numa opção mais abrangente, lastrada nos aspectos socioculturais. Se ficarmos com a primeira opção, as possibilidades de estudo limitam-se aos pequenos grupos de ativistas, pensadores e pessoas que se referem a si próprios com esta palavra. Entretanto, quando mudamos o ângulo para uma perspectiva sociocultural, a abrangência não só é maior como também pode incorporar novos sujeitos e, ao mesmo tempo, possibilitar a aplicação de nuances na análise.

Sirinelli sugere uma divisão tripartida no campo intelectual: os criadores das políticas culturais, seus receptores e os mediadores. Também sugere a possibilidade de acrescentar outra leitura, incorporando as categorias socioprofissionais de cada um desses tipos de intelectuais. Deste modo, constituem-se três grandes grupos: os grandes intelectuais, denominados de maitrê à penser, os mediadores e finalmente aqueles que Sirinelli (2003, p. 242-246) denomina de "despertadores", isto é, aqueles que formam e incentivam novos intelectuais. De alguma forma, a análise de Sirinelli acompanha, então, a análise de Gramsci (1979, p. 11), que dividia a categoria em vários estratos, propondo dois grandes pólos de referência: numa ponta, os criadores e, na outra, os divulgadores ou administradores. 
Finalmente deveríamos pensar como e de que forma devem ser estudados esses intelectuais. Não podemos concentrar toda a nossa atenção em suas concepções ideológicas, base da História das Ideias, e também não podemos focar em suas vidas, o que pode configurar o estudo de biografias. Podemos pensar em estudar a composição de campos, segundo a sugestão de Bourdieu, ou de trajetórias, segundo Sirinelli. Ambas as possibilidades não são excludentes, principalmente no tema que nos propomos a desenvolver aqui: a formação de um grupo de intelectuais vinculados com o Direito Trabalhista e com a política internacional. Afinal, suas trajetórias pessoais são importantes para a compreensão dos debates e posicionamentos dentro deles; porém não podemos esquecer que todos eles formam parte de um campo restrito como é a questão trabalhista. Exxitos e fracassos desses intelectuais são importantes, não unicamente vistos pelo plano individual, mas também pela possibilidade de reforçar as suas posições nos debates, nas suas posições políticas ou nas disputas de poder e prestígio no interior do aparelho do Estado.

\section{Intelectuais na América Latina}

Uma segunda questão é definir o intelectual na América Latina. Se partirmos dos primeiros intelectuais latinos e suas posições, a análise pode ser demasiado restrita. Em grande medida, aqueles que foram reconhecidos como os intelectuais da América Latina por antonomásia destacaram-se pelo fato de reunir dois campos diferentes: a literatura e a política. Se procurarmos aqueles indivíduos que foram elevados à categoria de cânone da intelectualidade nesta região, depararmo-nos com personalidades como as dos argentinos Domingo Faustino Sarmiento e Bartolomé Mitre, a do venezuelano Andrés Bello, ou a do cubano José Martí, entre tantos outros. Todos eles escreveram os ensaios e as poesias que determinariam os rumos 
da Literatura, da História e do Pensamento Social na região, ao mesmo tempo em que desempenhavam os mais altos cargos da política local ou regional ou foram referência na política de seus países. Esses intelectuais foram, portanto, modelos de políticos e de escritores, influenciando a forma da escrita e a da ação política. Assim, a partir deles é que se define o que é um intelectual na América Latina (PAMPLONA, 2003, p. 4-6).

Todavia esse é um ponto de vista reducionista e que limita a análise a essas grandes figuras ou a poucas outras posteriores, entre as quais poderíamos incorporar, por exemplo, José Vasconcelos e Pablo Neruda. Por isso, entendemos que é possível e desejável ampliar o escopo da análise a outros atores que também pensaram os rumos das Nações da América Latina ou, de uma forma mais modesta, alguma das suas áreas específicas. Nesse sentido, a nossa aposta é incorporar atores situados em posições intermediárias dentro do cânone intelectual da América Latina.

Esta opção nos leva a refletir sobre o papel do Estado na configuração da esfera intelectual, pois muitos dos intelectuais da região tiveram no Estado um ponto de apoio para o desenvolvimento das suas atividades, já que assumiram uma posição dentro do sistema político ou em instituições ligadas ao Estado, como professores ou funcionários públicos. Simultaneamente, esses intelectuais definiam um campo de ação e de relacionamento com o Estado e com a sociedade, o que os tornava mais sofisticados e com demandas mais complexas. Assim, os intelectuais se transformaram em uma necessidade para os funcionamentos estatal e social.

$\mathrm{Na}$ década de 1930, deparamo-nos com um feedback crescente entre Estado e Intelectuais. Podemos aqui simplificar o processo, dizendo que os intelectuais, por meio de órgãos de imprensa ou acadêmicos, formaram e informaram a opinião pública e demandaram tarefas que, posteriormente, foram executadas por eles próprios ou pelos aliados no campo intelectual daqueles que realizaram a reivindicação. 
A crise de 1930 levou a uma implosão dos sistemas de pensamento prévios baseados no liberalismo e no laissez faire, tanto no aspecto político como no econômico. Isso abriu as portas para a experimentação e a adaptação de novas ideias e estratégias políticas. Pessoas que não tinham espaço anteriormente, com pensamentos audaciosos e inovadores, com cartas de referência de instituições internacionais ou comprometidas com as ideias de ação triunfantes na política daquele momento - como o comunismo, o fascismo e, um pouco depois, o New Deal -, emergiram no cenário político, trazendo consigo uma forte renovação no âmbito intelectual. Contudo, os grupos que dominavam a cena não entregaram suas posições sem experimentar nenhuma reação. Pelo contrário, nessas disputas entre grupos e ideologias antagônicas, as posições no interior do Estado e os vínculos com a alta política foram decisivos para a manutenção dessas mesmas posições ou para determinar quem se tornava influente. No caso que analisamos aqui, as partes também tiveram que recorrer a fatores legitimadores de suas posições interiores ao Estado e fora dele, procurando ganhar apoio na instituição que seria o centro das disputas, a OIT, e ainda na opinião pública, por meio de debates jornalísticos.

\section{A OIT e a disputa dos modelos de pensar a questão social na Argentina}

A presença da OIT neste artigo justifica-se por considerarmos que ela seja o eixo de uma série de conflitos e posicionamentos em torno às novas aproximações à questão social por excelência, a questão trabalhista. Num período de transformações aceleradas da estrutura produtiva e social assim como das ideologias dominantes, a procura de um sistema estável e com o respaldo dos países centrais era de fundamental importância para os membros do Estado Argentino. Depois do Golpe Militar de $1930^{4}$, que se iniciou com uma 
primeira e frustrada experiência de restauração das elites agrárias no governo, foi preciso achar um novo rumo que incluísse o setor produtivo urbano e um sistema de pensamento que lhe proporcionasse sustentação ideológica, sem cair no fascismo. Uma possibilidade na Europa era a OIT, uma referência na área do Direito Trabalhista.

A Argentina fazia parte da OIT desde a sua criação e participava das reuniões anuais, como os outros países da América Latina, porém não estava totalmente incorporada ao organograma da instituição. A incorporação plena se efetivou com a instauração de um escritório de correspondência em $1931 .^{5}$

O correspondente da OIT tinha, dentre outras, a obrigação de divulgar suas atividades e fazer cumprir suas iniciativas. Também deveria preparar informes sobre a situação social, política, econômica e, principalmente, sobre as condições de trabalho e do funcionamento das leis trabalhistas nos países de atuação. Esses informes mostram que os correspondentes não eram simples correntes de transmissão. Eles deveriam estar preparados para discutir nas altas esferas do Estado e os relatos apresentam justamente um refinado conhecimento da política local. É por isso que analisaremos esses correspondentes como intelectuais, embora com uma esfera de ação um tanto limitada.

A aceitação da presença da OIT na Argentina não foi fácil, se pensarmos nos conflitos que, desde as suas origens, existiram entre este país e a Sociedade das Nações (SN). Inicialmente a OIT foi associada pelo governo argentino como um apêndice da $\mathrm{SN}$, o que dificultou essa relação. A rejeição da Argentina devia-se à influência dos Estados Unidos no interior desta instituição. ${ }^{6}$ Mas o reformismo de setores das classes médias e do operariado argentino favoreciam a aceitação da OIT e esta facilitava um diálogo com a SN. Estes grupos reformistas entendiam que o melhoramento das condições de vida e trabalho dos operários só podia ser garantido pela aceitação do papel do trabalhador na sociedade e não pela 
luta de classes. E a melhor forma de chegar ao consenso era por via da criação de uma legislação específica. Portanto, a OIT legitimava essa aspiração e colocava a fonte desse consenso numa instituição internacional. As disputas trabalhistas teriam como espaço o Congresso Nacional, local de discussão das Convenções e Acordos internacionais, enquanto os sindicatos, uma influência menor no debate, limitava-se à luta de classes. Como conseqüência dessas posições, a Argentina se manteve próxima da OIT ao longo da década de 1920, embora continuasse com uma posição hostil em relação à $\mathrm{SN}$.

Com a chegada ao governo do general Justo, a Argentina decidiu ratificar o Convênio da $\mathrm{SN}$, mesmo participando dela desde os seus inícios. ${ }^{7}$ A relação entre a Argentina e a OIT nunca foi oficialmente interrompida, mas a crise política e econômica de 1930 levou a uma suspensão informal do vínculo. A mudança de posição das relações exteriores da Argentina teve múltiplos desdobramentos, sendo o mais importante deles o êxito da sua diplomacia durante a Guerra do Chaco, o que permitiu ao então Ministro das Relações Exteriores, Carlos Saavedra Lamas, ser mais agressivo com os Estados Unidos, apoiando-se nos novos acordos alcançados com a Inglaterra e com os países europeus, produto da sua incorporação à SN (ESCUDÉ; CISNEROS, 2000, cap. 44). Em relação à OIT, Saavedra Lamas teve que lidar com o seu correspondente na Argentina, Raúl C. Migone.

A relação de Saavedra Lamas com Raúl Migone foi marcada pela disputa pelo controle da relação com a OIT. Neste sentido, os dois tentaram legitimar o vínculo com a instituição e, ao mesmo tempo, controlá-lo, seja pela tentativa de se apresentar como seu melhor intérprete ou pelo questionamento ao rival. As posições desses dois personagens no interior do Estado Argentino permitem-nos refletir sobre a composição de um campo intelectual ligado à legislação trabalhista. O conflito evidencia posições divergentes e, ao mesmo tempo, permite compreender a importância que esta 
temática tinha nas reflexões dos intelectuais e como ela mudou desde a sua emergência na sociedade argentina (FERRERAS, 2006).

Os personagens em questão tiveram trajetórias distintas e estavam em diferentes momentos de suas vidas profissionais, o que contribuiu decisivamente para o resultado final do embate e dos desdobramentos posteriores das reflexões neste campo. Saavedra Lamas era membro de uma família com uma linhagem que remontava à Revolução de Maio, de 1810. Quando, em 1932, assumiu como Ministro das Relações Exteriores, tinha uma vasta experiência política e acadêmica, além de uma importante produção na área do Direito, inclusive do Direito Trabalhista (SAAVEDRA LAMAS, 1933). Seus vínculos se alargavam para fora da Argentina. Como representante deste país, tinha participado e liderado a reunião anual da OIT de 1928. Sua influência no pensamento social e afinidade com a própria OIT fizeram de Saavedra Lamas uma referência internacional na literatura do Direito do Trabalho, tanto que Albert Thomas, o primeiro secretário geral da OIT, escreveu o prólogo do seu Código Nacional del Trabajo. ${ }^{8}$

Embora Saavedra Lamas fosse uma figura de primeira ordem da intelectualidade da Argentina, a reaproximação deste país com a OIT foi encomendada, por esta própria organização, a um membro de terceira ordem do Ministério das Relações Exteriores da Argentina, Raul Migone, sem que houvesse consulta a Saavedra Lamas. Migone passou de cônsul adjunto argentino em Genebra a negociador, nos bastidores, da aproximação entre a OIT/SN e a Argentina. $\mathrm{O}$ fato de ter sido recrutado em Genebra e de que, durante seu período como correspondente, fosse reatada a relação entre Argentina e a OIT, mostra a importância adquirida pelo operador, assim como o valor dado a este vínculo pelo governo argentino. Migone ${ }^{10}$ foi nomeado em 1931, antes que Saavedra Lamas chegasse ao cargo de Ministro das Relações Exteriores, mas sua presença como correspondente da OIT foi cada vez mais incômoda para o novo chanceler, que via neste funcionário um intruso nas discussões 
sobre as relações internacionais e a legislação trabalhista. O vínculo que se estabeleceu entre este ignoto funcionário e o chanceler nos permite pensar na forma de disputa pelo controle de um espaço de reflexão, a legislação trabalhista, e também da ação política, ao passo que se consolidava um espaço intelectual, com os seus mecanismos de apresentação, de legitimação e de disputa.

O General José Félix Uriburu, que assumiu a presidência depois do Golpe Militar de 6 de junho de 1930, teve uma política de boa vontade para com as Instituições Internacionais. Para demonstrar a importância dada por este governo à OIT, Uriburu resolveu que Raúl Migone, por ter sido nomeado correspondente da OIT, devia receber um novo cargo no Ministério das Relações Exteriores: o de Chefe da Seção encarregada da Sociedade das Nações. Migone recebeu, assim, o apoio das principais figuras políticas da Argentina, fossem estas da situação ou da oposição.

A mudança de Governo significou uma virada na situação de Migone. O novo ministro das Relações Exteriores, Carlos Saavedra Lamas, embora fosse favorável ao restabelecimento do vínculo entre a OIT e Buenos Aires, queria ser o protagonista desta aproximação. Para afastá-lo, Migone foi transferido da chefia das relações com a Sociedade das Nações a um cargo de cônsul em Encarnación (Paraguai). ${ }^{11} \mathrm{O}$ novo Ministro das Relações Exteriores tinha uma excelente relação com os novos membros da OIT. ${ }^{12}$ Harold Buttler, Secretário Geral da OIT, decidiu dar ouvidos aos pedidos de Saavedra Lamas. ${ }^{13}$

Como sua situação era cada vez mais difícil no Ministério, Migone optou pela renúncia, mantendo, porém, o cargo de correspondente. Suas possibilidades de ação, deste modo, ficaram restritas ao Congresso da Nação, onde se deparou com importantes aliados, como os Senadores Socialistas Alfredo Palacios e Mario Bravo e o Democrata Progressista Lisandro de la Torre ${ }^{14}$, além de um importante número de deputados dos mais diversos partidos, dos sindicatos de extração sindicalista e socialista e ainda alguns membros 
de menor hierarquia da administração pública com os quais mantinha relações pessoais. Em todos seus informes à OIT, Migone relatava com pessimismo as gestões realizadas ante o Ministério das Relações Exteriores e com otimismo as realizadas com outros atores sociais. De toda forma, ele conseguiu alcançar os objetivos propostos pelas autoridades da OIT: o retorno das delegações argentinas a Genebra para as convenções anuais, a ratificação da Seção XIII do Tratado de Versalles, a aprovação de boa parte dos Acordos estabelecidos pelas convenções e o pagamento das anuidades da Argentina à OIT. Também manteve a informação em dia sobre as questões políticas e econômicas e conseguiu impedir a criação de uma Organização Pan-americana do Trabalho, auspiciada pelos Estados Unidos, o Chile e o Uruguai. ${ }^{15}$

O que opunha Saavedra Lamas a Migone era o fato de que aquele tinha seu próprio homem de confiança e candidato ao cargo, Alejandro Unsaín. ${ }^{16}$ Savedra Lamas via em Unsaín a pessoa adequada para reconstituir os vínculos com Genebra, aproximando a OIT e a Sociedade, já que atuaria como um representante dos pontos de vista argentinos ante a OIT e não o inverso. Não por acaso, Unsaín tinha sido o representante argentino em várias assembleias anuais da OIT na década de 1920. A necessidade de fortalecer a instituição e de manter a influência na região, sem contar a amizade que lhe unia a Saavedra Lamas, fez com que Buttler preferisse o setor com maior capacidade de ação e potencial para apoiar ativamente a OIT.

Apesar do descontentamento de Migone com Unsaín, este não era um recém-chegado neste campo. Pelo contrário, o recémchegado era Migone. Em 1933, o Dr. Alejandro Unsaín era uma figura conhecida e importante, especialmente entre os advogados trabalhistas, entre os legisladores e os homens do governo. Sua extensa trajetória na área demonstrava que conhecia a lei e a prática. Unsaín tinha sido assessor do Ministro do Interior Joaquín V. González na redação do primeiro projeto de Lei do Trabalho. Embora este projeto não tenha chegado a se tornar lei, foi o ponto de partida para o estabelecimento de uma política trabalhista na 
Argentina que levou à criação do Departamento Nacional del Trabajo (DNT) e que seria a base do livro de Saavedra Lamas. ${ }^{17}$ Unsaín participou deste Departamento desde o início, em 1907, com o pequeno cargo de "Auxiliar $2^{\circ}$ de Contabilidade" e chegou ao cargo de presidente temporário, entre 1918 e 1920, desempenhando outras funções. ${ }^{18}$

Esses não eram os únicos antecedentes de Alejandro Unsaín nesse campo de estudos. Ele era um grande conhecedor das atividades da OIT. Quando fora presidente interino do DNT, Unsaín destinou dois números do Boletim do Departamento a cada uma das Conferências Internacionais do Trabalho reunidas em Washington (1919) e em Gênova (1920). ${ }^{19}$ Também representou a Argentina na Conferência Anual da OIT de 1927. A crítica à falta de experiência nas matérias era infundada e dificilmente acreditar-se-ia em Genebra. ${ }^{20}$ Evidentemente, Unsaín era um dos homens que tinha ajudado a criar uma área de reflexão e, ao mesmo tempo, era um antigo colaborador de Saavedra Lamas.

$\mathrm{Na}$ conformação de um campo de debates em torno à OIT e na configuração de uma ação por ela e com ela, as situações dos protagonistas eram diferentes. $\mathrm{Na}$ visão do chanceler argentino, a OIT era uma via de aproximação à $\mathrm{SN}$ e, portanto, tinha suma importância na sua estratégia. Esta aproximação foi paralela ao afastamento dos Estados Unidos destas instituições. O ano de 1936 foi decisivo na estratégia de Saavedra Lamas, pois foi quando ele recebeu o prêmio Nobel da Paz por sua mediação na Guerra do $\mathrm{Chaco}^{21}$, participação que deslocou os Estados Unidos do conflito e permitiu pospor seus interesses na região. Por este feito, foi recebido com entusiasmo na Sociedade das Nações. Ainda em dezembro daquele ano, desarticulou as intenções dos Estados Unidos de conformação de uma Organização Pan-americana, como proposto na Conferência Interamericana de Consolidação da Paz que teve lugar em Buenos Aires. Nesta nova situação, foi quase um detalhe a perda do cargo de Migone para Alejandro Unsaín. ${ }^{22}$ 
Os interesses de Unsaín na OIT não eram exatamente os mesmos de Saavedra Lamas, embora ambos estivessem coligados contra Migone. Unsaín era, como mencionado, um homem do aparelho estatal e acadêmico, especializado na questão trabalhista. Sua ambição pessoal era ser considerado uma referência na área e a isso tinha destinado seu trabalho dentro e fora do Estado, como advogado e como intelectual (GARGUIN, 2000, p. 93). Seu estreito e prolongado vínculo com o Departamento Nacional do Trabalho brindou-lhe com a oportunidade de intercambiar opiniões e visões compreensivas da questão trabalhista na Argentina e no mundo com profissionais do direito e da estatística (LOBATO, 2007). Unsaín, mesmo num governo conservador, representava o modelo de ação trabalhista do radicalismo, o qual se caracterizava por dar curso legal aos conflitos trabalhistas para que, assim, as soluções fossem aceitas com mais facilidade. Desta forma, as soluções ficavam fora da alçada do poder político, porque tinham um curso institucional. ${ }^{23}$

Isso ia de encontro às propostas da OIT de criar um sistema institucional para a questão trabalhista que evitasse as constantes lutas entre trabalhadores e patrões, deixando o Estado como recurso de última instância. A OIT ainda tinha interesses múltiplos na Argentina e estava interessada tanto em aprofundar seus lineamentos como em inserir a Argentina no sistema internacional, deixando de ser uma ameaça totalitária. Para Raul Migone, o seu interesse principal era tornar-se o representante da OIT para depois constituir-se como o articulador das políticas da SN na Argentina. ${ }^{24}$

As disputas entre esses três protagonistas se sucederam em diversos terrenos, desde o estritamente acadêmico até articulações políticas, como aconteceu no momento da ratificação do artigo 393 do Tratado de Versalles ${ }^{25}$, que se relacionou com a conformação da OIT. Raul Migone levantou uma série de intrigas sobre a posição de Carlos Saavedra Lamas, sugerindo que havia vínculos com a Itália fascista e que a demora da aprovação da Argentina devia-se ao fato de não ter havido ratificação recíproca entre Argentina e 
Itália. Porém, o próprio Migone entendia que esta era uma armadilha italiana em que teria caído Saavedra Lamas, dado que a Itália já tinha ratificado o ponto. Harold Buttler desautorizou Migone e interpretou que a demora devia-se a um descontentamento de Saavedra Lamas com as negociações pela Guerra do Chaco. ${ }^{26}$ Esta era uma forma extrema de resolução dos conflitos, mostrando as dificuldades existentes para a conformação de uma área de estudos, na qual a relação com o Estado e a sua própria posição no interior dele eram centrais para a consolidação dos projetos pessoais ou coletivos.

\section{Algumas conclusões}

O campo intelectual na área do Direito Trabalhista constituiu-se, em grande medida, na relação com o Estado. Enquanto os trabalhadores partiam para a luta ou para a organização partidária visando à intervenção nas relações trabalhistas ou a sua dissolução, a ação dos trabalhadores se baseava na criação de organizações ou instituições fora do Estado - embora, muitas vezes, este fosse chamado a intervir nas disputas com o Capital ou para reconhecer a existência de trabalhadores.

No Direito Trabalhista, o campo só se constitui a partir da função que deve ter o Estado. Sem este, não há Direito. Certamente, há tendências liberais, e, portanto, menos intervencionistas, porém, sempre há a relação do Estado com os trabalhadores. Os trabalhadores ou os proprietários podem cogitar deixar o aparelho estatal fora da resolução dos conflitos, todavia ao Direito cabe refletir como esses conflitos devem ser resolvidos num espaço de neutralidade aparente: o Estado. É por isso que ele é tanto o centro como o ponto de partida das análises desses intelectuais.

Não podemos deixar de considerar o fato de que militantes operários ou intelectuais próximos do movimento operário tenham 
se preocupado com a questão do Direito Trabalhista e que tenham intervindo nos debates em jornais ou periódicos próprios. Contudo, cada vez que isto acontecia, interpelavam o Estado ou alertavam os seus representantes (principalmente os deputados que recorriam ao voto dos trabalhadores) sobre como deveriam intervir. Por isso, o Estado está no centro das disputas quando falamos de legislação trabalhista.

Como mencionado anteriormente, deve-se refletir sobre quem pode e deve ser considerado como intelectual. Esses especialistas no Direito Trabalhista argentino são atores políticos, no sentido de que atuavam próximos do Estado, dos partidos políticos ou das organizações de trabalhadores, empresários ou setores destinados a essa questão, como a OIT; entretanto, não podemos desconsiderar o seu pertencimento ao campo dos intelectuais. As táticas, negociações e vínculos estabelecidos para impor as suas teorias ou reflexões não nos permitem deixar de lado o fato de que há reflexões e teorias.

Neste caso, confluem três posicionamentos diferentes em relação à imposição e alcances do Direito Trabalhista na Argentina e isso nos permite refletir sobre como se conforma um campo de debates e de ação dos intelectuais. Por um lado, temos que mencionar o fato de que estamos nos referindo unicamente a três atores de um campo que é muito mais amplo. Desse campo, participam outros intelectuais que formam parte das instituições consagradas em relação à questão social ou aos distintos partidos políticos que se preocupam com esta questão. Por outro lado, temos que mencionar que, ainda quando existam outros intelectuais renomados, na Argentina da década de 1930, as possibilidades de atuação fora do Estado são limitadas. Existem publicações e instituições que contribuem para a formação do campo, mas o Estado continua a ser decisivo. O Estado não é unicamente objeto das reflexões e posicionamentos desses intelectuais, é também quase que o único sustento deles. As possibilidades de trabalho no setor acadêmico ou nas suas distintas dependências são uma preocupação e um objetivo. 
No caso analisado, é evidente que Saavedra Lamas, Unsaín e Migone tinham objetivos diferentes e estavam em momentos distintos de suas vidas profissionais. Essas diferenças de status e possibilidades de atuação pública fizeram com que os desempenhos deles fossem também distintos.

Saavedra Lamas atuou na posição de Ministro das Relações Exteriores e foi um dos intelectuais de melhores relações do período, ao ponto de, em 1936, no mesmo momento dos debates e disputas pelo controle do escritório de Correspondência, aceder ao prêmio Nobel.

Raul Migone, por sua vez, foi um obscuro funcionário que se viu lançado à alta política e que teve de sustentar uma posição difícil ante as pessoas com recursos muito mais amplos. Migone não foi um grande intelectual, embora seus relatórios sobre a Argentina, apresentados na OIT, sejam muito interessantes, bem informados e com boas análises da realidade local ${ }^{27}$. Mas sua produção é limitada e apresenta interesse mais pela técnica do que pela reflexão (MIGONE, 1942). Mesmo assim, e com todas as suas limitações, Migone obteve, posteriormente, posições importantes, chegando ao cargo de Ministro do Trabalho em 1955, no governo que derrocou a Juan Domingo Perón.

Já Unsaín tinha objetivos mais próximos ao campo intelectual, participando como correspondente da OIT na Argentina e mantendo sua trajetória na área e influência do grupo político tradicional. Unsaín manteve-se ativo, neste campo de estudos, até sua morte, em 1952, depois do período de sua função como correspondente. Continuou a fazer parte dos quadros acadêmicos da Faculdade de Ciências Econômicas e do Museu Social Argentino, produzindo obras de referência na área (UNSAIN, 1935; 1942; 1943; 1945).

Os conflitos e tensões entre esses protagonistas do Direito Trabalhista na Argentina, alguns dos quais reconhecidos intelectuais, permitem-nos começar a refletir sobre a construção de campos intelectuais não restritos a questões mais abrangentes ou à totalidade 
social. Pelo contrário, a atuação num espaço delimitado, porém importante, numa sociedade em transformação e na passagem a uma sociedade de massas, urbanizada e industrializada, possibilita-nos perceber a importância do Estado para a construção desses novos espaços de pensamento e ação.

The Nobel Prize and the bureaucrat: the constitution of an intellectual field in Labor Law in Argentina in the 1930's

Abstract: This work aims to approach the formation of an intellectual field related to Labor Law in Argentina. Thus, we discussed the arguments established over the relation to the meanings of the International Labor Organization by leading figures of labor law in Argentina. These arguments had as main opponents the Minister of Foreign Affairs of Argentina, Carlos Saavedra Lamas, and a tiny employee of the same Ministry, Raul Migone. The control of this relation allowed the legitimacy of a speech and practice in this field of action.

Keywords: Labor Law. Intellectuals. International Labor Organization. Argentina.

\section{Notas}

${ }^{1} \mathrm{O}$ presente artigo é parte de uma pesquisa financiada parcialmente pelo $\mathrm{CNPq}$ (Edital de Ciências Humanas e Sociais A plicadas e Edital de Jovens Pesquisadores) e pela Faperj (Edital de Apoio às Ciências Humanas). Agradeço os esclarecedores comentários dos pareceristas anônimos e de Marina de Lira Rocha. Destaco que os erros e esquecimentos são da minha inteira responsabilidade.

2 Para uma aproximação às origens e aos usos da palavra "intelectual", sugerimos uma leitura do primeiro capítulo do livro de Sirinelli e Ory, 2007. Para os rumos atuais deste debate, ver Noiriel, 1997, cap. 4, destinado a analisar a crise dos paradigmas.

3 Referimo-nos ao processo de acusação, juízo e reabilitação do Capitão Alfred Dreyfus, durante a Terceira República Francesa, entre 1894 e 1906.

${ }^{4}$ O Golpe Cívico e Militar de 6 de setembro de 1930 derrocou o Governo de Hipólito Yrigoyen, líder da Unión Cívica Radical, abrindo um período de hegemonia política dos setores conservadores e liberais da Argentina e de exclusão dos setores populares da política.

${ }^{5}$ Apenas dois países foram incorporados nesse novo esquema pela OIT: a Argentina e o Brasil. As causas de cada uma dessas incorporações foram diferentes, mas o objetivo final foi o mesmo: ampliar a participação de países que estavam crescendo industrialmente e compensar as saídas das grandes potências industriais.

Anos 90, Porto Alegre, v. 16, n. 29, p.213-236, jul. 2009 


\section{Norberto O. Ferreras}

${ }^{6}$ Para maiores detalhes sobre estes conflitos, ver Escudé e Cisneros, 2000, cap. 36. O presidente da Argentina explicitava a sua rejeição da influência dos Estados Unidos na Sociedade de Nações desde o momento mesmo da criação da instituição. Ver Irigoyen, 1956.

${ }^{7}$ Justo ganhou as eleições presidenciais de 1931, permanecendo no poder de 1932 até 1938. Ele era liberal e favorável à reintegração da Argentina ao mundo, tanto do ponto de vista econômico quanto diplomático (JUSTO, 1934, p. 56).

${ }^{8}$ Carlos Saavedra Lamas nasceu em 1878 e morreu em 1959. Alguns dos cargos ocupados por ele, antes de ser nomeado Ministro das Relações Exteriores, foram o de Deputado Federal pela cidade e pela Província de Buenos Aires e o de Ministro de Justiça e Instrução Pública, em 1915. Anteriormente, em 1903, tinha ocupado a Cátedra de Direito Constitucional na Universidade de Buenos Aires e, na década de 1920, criou a Cátedra de Sociologia. Vale a pena mencionar o seguinte livro: Saavedra Lamas, 1927. ${ }^{9}$ Raul Migone nasceu em 1898 e morreu em 1978. Saavedra Lamas não fazia parte do governo no momento da nomeação de Migone. Este ingressou pelos contatos dos governos e funcionários radicais que foram consultados antes que se efetivasse o Golpe Militar de 1930.

${ }^{10}$ Migone foi correspondente da OIT na Argentina, de março de 1931 a maio de 1936. Seu vínculo com a OIT estendeu-se, porém, para além dessas datas. Em 1936, foi incorporado ao serviço de Publicações da OIT. Em setembro de 1938, retornou à Argentina na tentativa de recuperar o cargo de correspondente. Finalmente, entre setembro de 1946 e Fevereiro de 1947, trabalhou como tradutor da OIT em Montreal (Canadá).

${ }^{11}$ OIT, National Correspondence and Branch Offices File C2 1932: Carta de Eduardo Migone a Harold Buttler, 8 out. 1932 e carta de Carlos Saavedra Lamas a Harold Buttler, 28 nov. 1932.

${ }^{12}$ Era evidente a diferença entre os oponentes: Saavedra Lamas foi presidente da Assembléia Anual da SN em 1936, ano em que recebeu o Prêmio Nobel da Paz por sua mediação na Guerra do Chaco.

${ }^{13}$ Albert Thomas foi o Secretário Geral da OIT entre 1919 e 1932, ano de sua morte. Harold Buttler esteve no comando da OIT desde 1932 até 1938. Para conhecer as principais atividades durante as Secretarias Gerais de Thomas e Buttler, ver Alcook, 1971. ${ }^{14}$ Mencionamos só esses deputados pelo fato de serem as principais lideranças de seus partidos, os quais eram, aliás, os principais partidos opositores com representação no Congresso da Nação, ante a abstenção eleitoral decidida pela UCR, que denunciava com fundamento a prática de fraude eleitoral por parte do governo Nacional.

${ }^{15}$ International Labor Organization. Correspondence. Argentine. Correspondent Office: Dr. Raul Migone (1931-1937).

${ }^{16}$ Alejandro Unsaín nasceu em 1881 e morreu em 1952. Era catedrático na Faculdade de Ciências Econômicas, além de ter ocupado o cargo de Presidente do Departamento

Anos 90, Porto Alegre, v. 16, n. 29, p. 213-236, jul. 2009 


\section{O Prêmio Nobel e o burocrata...}

Nacional do Trabalho (DNT), em 1918 e em 1920. Foi o redator do primeiro código do Trabalho na Argentina. Por ter participado dos governos da UCR, era tido como suspeito por muitos dos membros da administração nacional.

${ }^{17}$ Para uma análise desta primeira lei, ver: Zimmermann, 1995, p. 178 a 187. Esse texto foi a base do livro redigido, em 1928, por Saavedra Lamas e publicado finalmente em 1933. Ver Código Nacional del Trabajo, op. cit.

${ }^{18}$ República Argentina. Ministerio del Interior. Departamento Nacional del Trabajo. Boletín del Departamento Nacional del Trabajo, Buenos Aires: DNT. Os dados das posições ocupadas por Unsaín estão detalhadas nos números 1 (de 30 de junho de 1907), 37 (de março de 1918) e 116 (de outubro de 1927).

${ }^{19}$ República Argentina. Ministerio del Interior. Departamento Nacional del Trabajo. Boletin del Departamento Nacional del Trabajo. Buenos Aires: DNT. Os dados estão presentes nos números 45, de fevereiro de 1920, e 47, de setembro de 1920.

${ }^{20}$ República Argentina. Ministerio del Interior. Departamento Nacional del Trabajo. Boletin del Departamento Nacional del Trabajo. Buenos Aires: DNT, n. 116, oct. 1927.

${ }^{21}$ Assim é conhecida a Guerra entre a Bolívia e o Paraguai, ocorrida entre os anos de 1932 a 1935. A disputa teve como objetivo o controle da região denominada de Grande Chaco, onde se suspeitava que existisse petróleo.

22 A saída do cargo de correspondente não está muito bem explicada na troca de cartas entre as partes e, de fato, deve ter sido mencionada pessoalmente. Migone passou a atuar em Genebra, no setor de publicações. Ver International Labor Organization. Dossier du Service du Personal: Raul Migone.

${ }^{23}$ A té o momento de aceder ao cargo de Correspondente da OIT, Unsaín tinha publicado vários livros destinados a essa questão e continuaria a fazê-lo depois de deixar esse cargo. Alguns dos títulos eram: Unsaín, 1915; 1917; 1919; 1925; 1927; 1928.

${ }^{24}$ OIT, National Correspondence and Branch Offices File C2 1933: Memorando de Harold Buttler, 5 out. 1933, ratificado por Buttler em correspondência pessoal a J. Buero, 12 out. 1933. Migone se queixava ante a possibilidade de que um representante da SN fosse nomeado, o que, segundo ele, poderia complicar "os seus esforços". No entanto, o nome cogitado era o dele próprio: National Correspondence and Branch Offices File C2 1934: correspondência de Eduardo Migone a Lawford Childs, 09 nov. 1934.

${ }^{25}$ Esse artigo determinava que os Estados de maior importância industrial eram aqueles que tinham maior influência na conformação do Conselho de Administração da OIT. A reforma foi realizada em 1935. A informação está em: OIT. Consejo de Administración Comisión de Cuestiones Jurídicas y Normas Internacionales del Trabajo. 300ª reunión Ginebra, nov. 2007 http://wwwilo.org/wcmsp5/groups/ public/—ed_norm/—relconf/documents/meetingdocument/wcms_084562.pdf, consultado no dia 24 fev. 2009.

Anos 90, Porto Alegre, v. 16, n. 29, p.213-236, jul. 2009 


\section{Norberto O. Ferreras}

${ }^{26}$ OIT, National Correspondence and Branch Offices File C2 1934: correspondência de Eduardo Migone a Harold Buttler, 12 maio 1934, 29 maio 1934 e 2 jun. 1934; carta de Lawford Childs a Migone, 22 maio 1934 e 6 jul. 1934; carta de Migone a Lawford Childs, 15 maio 1934, 19 maio 1934 e 15 jun. 1934.

${ }^{27}$ Para maiores dados sobre seus relatórios, ver: International Labor Organization. Cabinet Albert Thomas. Argentine. Relations et Informations. Correspondent avec Dr. Raul Migone.

\section{Referências}

ALCOCK, Anthony. History of the ILO. London: Macmillan, 1971.

BOURDIEU, Pierre. Campo de poder, campo intelectual. Itinerario de un concepto. Buenos Aires: Montressor, 2002.

DEBRAY, Regis. I.F. Suite et fin. Paris: Gallimard, 2000.

DOSSE, François. La marcha de las ideas: historia de los intelectuales, historia intelectual. Valencia: Universitat de Valencia, 2007.

ESCUDÉ, Carlos e CISNEROS, André. Historia de las Relaciones Exteriores de Argentina. Buenos Aires: GEL editores, 2000.

FERRERAS, Norberto O. A formação da sociedade Argentina contemporânea: sociedade e trabalho entre 1880 e 1920. História, v. 25, n. 1. São Paulo: Franca, 2006.

GARGUIN, Enrique. Relaciones entre Estado y Sindicatos durante los gobiernos radicales, 1916-1930. In: PANETTIERI, José. Argentina: trabajadores entre dos guerras. Buenos Aires: Eudeba, 2000.

GRAMSCI, Antonio. Os intelectuais e a organização da cultura. Rio de Janeiro: Civilização Brasileira, 1979.

IRIGOYEN, Hipólito. Mensaje Presidencial de 1921. In: IRIGOYEN, Hipólito. Pueblo y Gobierno. IV. Mensajes inaugurales del Congreso de la Nación. Buenos Aires: Raigal, 1956.

JUSTO, Agustín P. Mensaje del Señor Presidente de la Nación Agustín P. Justo. Al inaugurar el periodo ordinário de sesiones del H. Congreso de la Nación. 1934. Buenos Aires: Talleres Gráficos del Ministerio de Agricultura de la Nación, 1934, p. 56.

LOBATO, Mirta. Historia de las instituciones laborales en Argentina: una asignatura pendiente. Revista de Trabajo. Año 3, n. 4. Buenos Aires: Ministerio del Trabajo, ene./nov. 2007. 


\section{O Prêmio Nobel e o burocrata...}

MIGONE, Raúl C. Anuario estadístico interamericano. Buenos Aires: El Ateneo, 1942.

NOIRIEL, Gerard. Sobre la crisis de la Historia. Valencia: Universitat de Valencia, 1997.

NORA, Pierre. Adieu aux intellectuels? Le Débat, n. 110. Paris: Gallimard, mai./ août. 2000.

OIT, National Correspondence and Branch Offices File C2 1933

PAMPLONA, Marco Antonio. Ambiguidades do pensamento latino-americano: intelectuais e a ideia de nação na Argentina e no Brasil. Estudos Históricos, n. 32. Rio de Janeiro: FGV, 2003.

SAAVEDRA LAMAS, Carlos Alberto. Centro de legislación socialy del trabajo. Buenos Aires: Imprenta de la Universidad, 1927.

. Código Nacional del Trabajo. 2 volúmenes. Buenos Aires: La Facultad, 1933

SIRINELLI, Jean-François e ORY, Pascal. Los intelectuales en Francia. Valencia: Universitat de Valencia, 2007.

SIRINELLI, Jean-François. Os intelectuais. In: RÉMOND, René. Por uma História Política. Rio de Janeiro: FGV, 2003.

UNSAÍN, Alejandro. Manual de la legislación obrera argentina. Buenos Aires: Compañía Sud-Americana de Billetes de Banco, 1915.

- Apuntes de legislación del trabajo en la República Argentina. Buenos Aires: Imp. Escoffier, Caracciolo y Cía., 1917.

Legislación social argentina: diccionario elemental. Buenos Aires: Talleres gráficos argentinos de L. J. Rosso y Cía, 1919.

- Legislación del trabajo. Tomo I. Buenos Aires: Valerio Abeledo, 1925.

. Legislación del trabajo. Tomo II. Buenos Aires: Valerio Abeledo, 1927.

. Legislación del trabajo. Tomo III. Buenos Aires: Valerio Abeledo, 1928.

. Empleados de comercio. Buenos Aires: Valerio Abeledo, 1935.

. Ordenamiento de las Leyes Obreras Argentinas. Buenos Aires: Losada, 1943.

- Programa de Politica Social. Buenos Aires: Universidad de Buenos Aires -

Facultad de Ciencias Económicas, 1945.

. Trabajo a domicilio: exposición y comentario a la ley número 12.713. Buenos Aires: Valerio Abeledo, 1942.

ZIMMERMANN, Eduardo. Los liberales reformistas. La cuestión social en la Argentina. 1890-1916. Buenos Aires: Sudamericana, 1995.

Anos 90, Porto Alegre, v. 16, n. 29, p.213-236, jul. 2009 